\title{
Religion and psychiatry: clinical applications
}

\author{
Harold G. Koenig ${ }^{\circledR}$, John R. Peteet \& Tyler J. VanderWeele
}

\section{ARTICLE}

\begin{abstract}
SUMMARY
In an earlier article we reviewed the latest research on the relationship between religious involvement and mental health, the effects of religiosity on mental health and well-being over time and the impact of religious interventions. Here we focus on clinical applications that may be useful to psychiatrists and other mental health professionals. We discuss general clinical applications relevant to all patients (e.g. taking a spiritual history, supporting/encouraging religious beliefs, referring to clergy), violations of clinician-patient boundaries and the need to ensure that religious/ spiritual interventions are patient-centred. We describe evidence-based religious interventions and how to identify appropriate patients for this approach. Finally, we explore situations in which religious beliefs and practices may be a problem, not a resource, and make recommendations on how to address such cases. Case vignettes illustrate clinical situations that mental health professionals are likely to encounter. Although the focus is on the North American context, we note how practice and culture in the UK may differ.
\end{abstract}

\section{LEARNING OBJECTIVES}

After reading this article you will be able to:

- better understand how the majority of psychiatrists during the 20th century viewed patients' religious beliefs and practices

- know how to take a spiritual history and other sensible ways to integrate religion/spirituality into clinical practice

- recognise when religion is a problem and how to approach patients in that case.

\section{DECLARATION OF INTEREST}

H.G.K. is Director of the Center for Spirituality, Theology and Health at Duke University Medical Center, Durham, North Carolina, USA.

\section{KEYWORDS}

Religion; psychiatry; spiritual history; boundaries; prayer.

The evidence base documenting the effects of religious involvement on mental health is growing rapidly, and much of it shows that religion has beneficial effects on mental health and well-being
(Koenig 2020). The view during the 20th century that religion is primarily neurotic was driven by the perspectives of influential individuals such as Francis Galton, Jean-Martin Charcot, Sigmund Freud and Albert Ellis (Koenig 2012, pp. 58-63). Even today, religious manifestations of mental illness are common, which certainly affected the opinions of early mental health professionals without access to the systematic research available today.

These negative views of religion had a significant impact on the care provided by mental health professionals, and at that time, the existing research did not help matters. In a review published in the American Journal of Psychiatry, Sanua (1969) concluded that "The contention that religion as an institution has been instrumental in fostering general well-being, creativity, honesty, liberalism, and other qualities is not supported by empirical data. Both Scott [...] and Godin [...] point out that there are no scientific studies which show that religion is capable of serving mental health'. A later examination of 45 case examples in the DSM-III-R glossary of technical terms found that $22.2 \%(n=10)$ had substantial religious content, including references to illogical thinking, incoherence, poverty of affect, catatonic posturing, delusions of being controlled, hallucinations, magical thinking and other types of delusion (Larson 1993). Around the same time a survey of 231 British psychiatrists at general and psychiatric hospitals in London found that almost three-quarters (73\%) reported no religious affiliation and $78 \%$ attended religious services less than once a month (Neeleman 1993). Only 19\% of male psychiatrists believed in God. A survey of American psychiatrists around that time found that $60 \%$ were atheist or agnostic and more than $60 \%$ rarely or never attended religious services (Franzblau 1975).

Even in one of the most religious regions of the USA (the 'Bible Belt'), staff on the psychiatry wards of Duke Hospital confiscated patients' Bibles when admitted, returning them only at the time of discharge. Patients were not even allowed to see a Duke Hospital chaplain unless the attending psychiatrist wrote an order for it (Koenig 2005, p. 26).

Today, in part because of a body of research indicating that religious practice can sometimes be a powerful resource for mental health (e.g., Miller 2014; VanderWeele 2016; Koenig 2018), the
Harold G. Koenig, MD, is Professor of Psychiatry at Duke University Health System; Director of Psychiatric Services in the Geriatric Evaluation and Treatment Clinic, Duke University Medical Center; and Director of the Center for Spirituality, Theology and Health at Duke University Medical Center, Durham, North Carolina, USA. He also serves as adjunct professor in the

Department of Medicine, Division of Psychiatry, King Abdulaziz University, in Jeddah, Saudi Arabia, where he is a research consultant.

John R. Peteet, MD, is Associate Professor of Psychiatry at Harvard Medical School, Boston,

Massachusetts, USA. He has published extensively on the ethical and clinical aspects of integrating religion/spirituality into psychiatric care. $\mathrm{He}$ is Director of the Psychosocial Oncology/Palliative Care Fellowship at the Dana-Farber Cancer Institute and a clinical psychiatrist at the Brigham and Women's Hospital, Boston, Massachusetts.

Tyler J. VanderWeele, PhD, is Loeb Professor of Epidemiology in the Departments of Epidemiology and Biostatistics at Harvard's T.H. Chan School of Public Health, Boston, Massachusetts, USA, where he has focused on the application of causal inference to epidemiology. He is a Fellow of the American Statistical Association and has received the COPSS Presidents' Award from the Committee of Presidents of Statistical Societies. Correspondence Harold G. Koenig. Email: Harold.Koenig@duke.edu

First received 2 Jan 2020 Final revision 3 Feb 2020 Accepted 10 Feb 2020

\section{Copyright and usage} (C) The Authors 2020 
situation is very different. Guidelines from the World Psychiatric Association (Moreira-Almeida 2016), the American Psychiatric Association Committee on Religion and Psychiatry (1990) and the Royal College of Psychiatrists (Cook 2013a) recommend that mental health professionals take a spiritual history to determine the role that religion plays as either a resource or a liability. Mental health professionals are likely to encounter patients who are religious because a significant proportion of the population reports that religion is important in their lives (27\% in the UK, 32\% in Australia, 54\% in Ireland, 65\% in the USA; Crabtree 2009). For these individuals, religious/spiritual beliefs are likely to influence the expression of psychiatric symptoms, how they cope with those symptoms and the degree to which they comply with treatment (which may or may not be compatible with those beliefs).

In this article, we describe applications to clinical practice based on the present state of knowledge, clinical experience and common sense (from a North American perspective), with fictitious case vignettes to illustrate situations that mental health professionals may encounter. Clinical applications are divided into (a) general applications, (b) evidencebased religious interventions and (c) situations where religion may be the problem.

\section{General applications}

General applications are relevant to all psychiatric patients, regardless of religious/spiritual belief or lack thereof.

\section{The spiritual history}

Perhaps the most important application for psychiatrists and other mental health professionals is taking a spiritual history. The spiritual history is an intervention in itself, as well as an information-gathering tool that can be useful in acquiring information about the patient that might otherwise not come up (since this is a sensitive area and patients may be reluctant to discuss it). However, patients may also be unwilling to discuss these concerns with clergy, family or friends because of fear that it will be embarrassing or provoke arguments. Thus, the patient may be left alone to struggle with distressing religious or spiritual problems, unable to share with anyone. Conflicts in this area may arouse powerful emotions unless dealt with and processed with someone.

\section{Case vignette 1: loss of faith}

Wilson is a 23-year-old unmarried, unemployed car mechanic being seen for the first time by a psychiatrist, Dr Thomas, for depressive symptoms that he has had for about 2 months.

During the intake evaluation when social and family issues are being explored, Dr Thomas asks
Wilson if he has a religious affiliation. Wilson responds, 'Yes, I'm Anglican, but not very involved in a church'. Dr Thomas follows with, 'Were you ever more involved in a church than you are now?' Wilson responds, 'Yes, a lot more, until I had a falling out with the priest about 6 months ago. I asked an attractive lady in the congregation to go out with me for a show and dinner. I didn't know she was married, but when I told the priest that, it didn't seem to matter. He told me it was wrong. What right did he have sticking his nose in my business? I haven't set foot in that church again'. Dr Thomas then asked, 'How has this experience affected your religious beliefs?' Wilson responded, 'I don't think much about religion these days and I'm not even sure I still believe in God. I feel bad about that because I grew up in a religious home and religious beliefs had always been important to me, especially since they helped me deal with the funk I fell into after my girlfriend broke up with me 2 years ago'. Dr Thomas responds, 'Do you think this concern over your faith has anything to do with your depression?' Wilson replies, 'I don't know. It might have something to do with it. I got fired from my job about 2 months ago. I really loved that job, and after they let me go, I started feeling sad and worthless. I tried using my religious beliefs to make sense of it, but all those doubts I've been having about God, and lack of any contact with my old church friends, have made it difficult to rely on my faith like I did before. I haven't made much effort to find a new job, have stopped socialising except in bars, and feel angry at God for letting all this happen to me. I feel like God, if he does exist, has deserted me or might be punishing me for not going to church anymore. What do you think I should do, doctor?'

Taking a spiritual history may be a new and uncomfortable activity for many practitioners who have not done it before. In the vignette above, Dr Thomas started out gradually by first asking the patient's religious affiliation, and as more information was provided, continued to explore the situation by getting the patient to talk about his beliefs, including his past experiences with religion and how those might have influenced his current situation. When taking a spiritual history, the mental health professional should proceed slowly, first asking general questions and then more specific ones as information is uncovered, seeking relevant details about the patient's current and past religious/spiritual beliefs and practices. In particular, the clinician should identify religious/spiritual struggles or conflicts, especially when there has been a recent change in belief or practice.

\section{Initiating spiritual history-taking}

The following may be helpful when initiating a spiritual history. Begin with a general statement such as: 'Many people have strong spiritual or religious beliefs that shape their lives, including their health and experiences with illness. If you're comfortable talking about this topic, would you please share any of your beliefs and practices that you might want me to know as your clinician' (Mathai 2003). 
Our research update included a list of 15 questions (Box 2 in Koenig 2020) as an example of the type of information that might be gathered. To summarise, first find out whether the patient has a religious affiliation or considers themselves to be a religious/ spiritual person and, if not, determine whether this has always been so. One can then explore what kind of religious or spiritual environment the individual grew up in, and whether this was a positive or negative experience. Determine whether the individual has ever had a significant change in religious/ spiritual beliefs, whether positive or negative. If religion/spirituality is important to them or has been in the past, ask whether religious/spiritual beliefs have ever been a source of comfort or a source of stress. Ask whether they are a member of a religious community and whether this is supportive or not. For patients who are religious/spiritual, assess whether they have any beliefs that might influence their willingness to take medication, receive psychotherapy or engage in other aspects of psychiatric care. For example, it may be quite important to determine whether a patient is a member of a conservative evangelical group that opposes medications or whether a Muslim patient requires a psychotherapist of the same gender. Also, if the patient is religious or more broadly spiritual, ask whether incorporating their religious/spiritual beliefs in treatment is desired. Finally, inquire about any other religious/ spiritual needs or concerns they wish to have addressed. If the patient is not religious/spiritual and has never been, then the spiritual history can be shortened.

\section{Case vignette 2: religion as a negative influence}

Sarah is a 53-year-old married woman admitted to the psychiatric ward for treatment of severe depression with suicidal thoughts. She has an unhappy marriage and is alienated from her husband. Her two teenage sons are not doing well at school, having recently been caught skipping classes and using drugs after school. Sarah says she feels overwhelmed, unhappy and just wants to die.

During the initial intake evaluation, following questions about her social and family life, the psych iatrist asks Sarah whether she has any religious/spiritual beliefs that provide comfort or increase her stress. Sarah responds, 'I've never been very religious, and religion has not been of any help in my family situation. My husband is very religious, and I think this is part of the problem. We frequently have arguments over religion. He wants our sons to attend services with him at the Catholic church, but I feel they have a right to make their own decisions in this regard'. The psychiatrist then asks, 'Do you think these conflicts over religion have contributed to the way you are feeling now?'. Sarah responds, 'Well, it certainly hasn't helped our marriage. He's become so fanatical about his beliefs that it has put a great distance between us. I feel so sad about that and very lonely'. The psychiatrist then asks, 'Do you think your husband would be willing to join us to talk about this issue?' Sarah agrees and says, 'I know he's not happy in our marriage either. He might be open to that'.

The spiritual history must be taken in a gentle, sensitive and non-judgemental manner. Clinicians often have their own feelings about religion/spirituality (either negative or positive) and need to be aware of their own countertransference reactions, which may require considerable effort. Unless the clinician remains open, kind and neutral, the patient may seek to please the clinician with their responses, argue with the clinician or shut down entirely. Taking a spiritual history involves a dance between the patient and mental health professional, with gentle prompting by the clinician while allowing the patient to lead where the conversation goes.

Although the best time to take a spiritual history is during the initial evaluation, this information can also be gathered over several encounters, particularly if there is initial resistance to the topic. Religion/spirituality is often considered personal, and patients may not be willing to reveal their thoughts and feelings about this subject until a comfortable and safe relationship has developed. For this reason, the spiritual history should never be forced on the patient and, in some cases, it is advisable to wait until the timing is better. Once an initial spiritual history has been taken, the clinician may need to delve deeper during future visits if religion/spirituality is important to the patient and affecting their mental health. Besides taking a spiritual history, what else might clinicians do?

\section{Supporting the patient's beliefs}

After taking a thorough spiritual history and developing a relationship with the patient over several visits, the clinician will have a sense of whether the patient's religious/spiritual beliefs and practices are contributing to mental health problems or, alternatively, helping them to cope. If, on the one hand, religious/spiritual beliefs appear to be contributing to the patient's illness, then the clinician will need to determine whether religion itself or the patient's use of religion seems to be the cause (see 'When religion is the problem' below). If, on the other hand, the patient's religious/spiritual beliefs appear to be a helpful resource to combat the illness, then the clinician may decide to support those beliefs. This must be done cautiously, since it is a departure from clinician neutrality and may have implications for the therapeutic relationship. Nevertheless, such support may boost the effectiveness of the patient's efforts to use their religious faith to cope and may even improve the clinician-patient relationship. 


\section{Encouraging religious participation}

When treating religious/spiritual patients who have previously found religious/spiritual activities helpful but stopped those activities, the clinician may encourage the patient to resume their involvement if there are no countervailing reasons against such participation. This represents an even a further departure from neutrality than supporting religious/ spiritual beliefs and practices already engaged in, underscoring the need for caution in making such recommendations. However, in some cases, encouraging religious participation may serve as part of the psychiatric treatment. For example, in a religious patient who no longer attends religious services and has persistent feelings of loneliness and social disconnection, the clinician may gently explore the possibility of their re-engaging with their faith community or other social group. Extensive research indicates that communal religious participation is associated over time with many positive mental and physical health outcomes (VanderWeele 2017; Koenig 2020). Barriers and resistances to such participation should be identified and discussed in a neutral and non-judgemental manner, as usual.

When making suggestions, clinicians should always proceed in a patient-centred manner and never attempt to proselytise patients, i.e. to convince them to believe or practise as the clinician does. Proselytisation crosses important boundaries between clinician and patient and violates the clinician-patient relationship, given the dependent and vulnerable position that patients occupy in this relationship (Koenig 2013; Peteet 2019). Mental health professionals in particular must avoid breaching boundaries of this type in order to maintain the therapeutic relationship. However, if a patient asks about the clinician's own religious/spiritual beliefs, and the clinician feels comfortable sharing those beliefs, a brief matter-of-fact response may be appropriate. If the clinician feels uncomfortable sharing their beliefs, it can be helpful to ask why the patient wishes to know, explaining that this will help the clinician better understand the patient. If the patient persists in requests for such information, clinicians have a right to refuse to share personal beliefs, although such refusal should be done in a sensitive and caring manner that does not alienate the patient.

\section{Participating in religious activity with the patient}

Engaging in religious/spiritual activities with patients, for example praying, goes beyond simply supporting a patient's religious/spiritual beliefs or encouraging religious/spiritual activity. This is a non-neutral form of clinician behaviour and is seen by some, especially in the UK, as a potentially concerning activity that involves a transgression of clinician-patient boundaries (Poole 2011). Besides praying, activities of this type include attending religious services, engaging in religious rituals and reading or reciting religious scriptures with patients. While such activities, if patient-centred and patientinitiated, may be beneficial to patients in some situations and should not be ruled out entirely, there is potential for harm (Poole 2019), especially when clinician-initiated (Dagi 1995). A history of issues surrounding clinician-patient prayer and similar controversies from a UK perspective is summarised elsewhere (Cook 2013b).

In other cases, however, where the cause of the patient's symptoms is clearly situational (e.g. due to traumatic stress or severe loss), a brief patientinitiated prayer with a willing clinician may be appropriate and viewed by the patient as a sign of compassion and care. In those instances, it may be optimal for the patient to say the prayer and the clinician to listen quietly and agree at the end with an 'amen'. The clinician may learn a great deal from the content of the patient's prayer, such as what they consider most important in their lives and things that may be relevant to their treatment. Prayer with patients can therefore be viewed as a form of information gathering.

However, similar to when patients ask about the clinician's personal religious beliefs, mental health professionals should never feel obligated to pray with patients even when asked. Instead, as before, a gentle inquiry as to why the patient wishes to pray with the clinician may uncover important information and subtly distract the patient from the request. If the patient insists (which is unlikely), and the clinician feels uncomfortable, the clinician may gently suggest that such activity is best done with a religious professional. However, it may be easier to just have the patient pray and then say amen at the end of the prayer ('amen' simply means 'so be it' and does not necessarily endorse religious belief).

\section{Referral to clergy}

Less controversial than encouraging religious activity or engaging in religious activities with patients is referral to clergy. Even this action, however, is not without risk. Patients may view a referral to clergy as a form of abandonment. This is especially true when patients have experienced difficulty discussing religious problems with clergy because of guilt, shame or embarrassment. Some indications for referral are when religious issues are important to the patient, religious/spiritual struggles are present, symptoms are not too severe and the clinician knows little about the patient's faith tradition. Consultation with clergy may be especially useful 
when there is conflict between religious beliefs and proposed treatments (psychotherapy or medication).

If referral to clergy is decided on, the next question is to whom to refer. If a member of the patient's own clergy is willing, preferred and adequately trained to provide such help, then this might be the best option. If not, then the choice of religious professional will depend on the severity of the patient's psychiatric condition, complexity of the religious problem, and availability and cost of services in the patient's location. Referral to a pastoral counsellor, religious counsellor or chaplain are all possibilities.

In the USA, pastoral counsellors are licensed mental health professionals with a master's or doctoral degree in counselling who offer evidencebased secular counselling from a religious perspective. Religious counsellors, similar to pastoral counsellors, are licensed mental health professionals who provide mental health counselling, but from a specific faith tradition (e.g. Christian counsellors, Hindu counsellors, Muslim counsellors, etc.). Religious counsellors often rely heavily on the scriptures of their faith tradition (such as the Qur'an or the Bible) to guide their clients. An example of a religious counselling organisation is the American Association of Christian Counselors (AACC). This is a large organisation with a worldwide membership of nearly 50000 (approximately half the size of the American Psychological Association membership and one-third more members than the American Psychiatric Association).

Chaplains are religious professionals who usually have a master's degree in divinity (MDiv) and have completed a course in clinical pastoral education (CPE), which prepares them to provide pastoral care and support, but not 'counselling', since they are not licensed professional counsellors (at least in the USA). Chaplains almost always have more training in counselling than community clergy and may be specialised in areas such as mental health.

Pastoral and religious counsellors are not available in the same way in the UK, and where religious counselling is offered, most practitioners will not have a master's or doctoral degree. The comparable organisation in the UK to the AACC would be the Association of Christian Counsellors. Most chaplains in the UK will not have an MDiv degree, CPE courses are all but completely absent in the UK and many chaplains are lay. Very few have counselling training of any kind. In many mental health settings, the chaplaincy department has been renamed the 'spiritual care' department or something similar.

\section{Case vignette 3: collaborative care}

Imam Abdelrahman (a community clergyman) is seeing Bakir, a 58-year-old lawyer and member of his mosque who has severe anxiety. Bakir is concerned that his 'bad deeds' outweigh his 'good deeds' and that he may spend eternity in hell paying for his sins after death. The imam has suggested several passages from the Qur'an to help relieve Bakir's anxiety and has encouraged him to recite these passages and spend time meditating on them. Imam Abdelrahman has also offered practical advice to help Bakir in making day-to-day decisions regarding his job, family and religious activities.

Bakir has met with Imam Abdelrahman about half a dozen times now, but he still worries about everything, especially the Day of Judgement, when he fears he will not be allowed into Paradise. In fact, his worries have grown worse and more intense over time, as he recently started waking up at night with panic attacks. Given his lack of progress, the imam suggests he seek professional help from a respected Muslim psychiatrist and asks whether Bakir would allow him to speak with the psychiatrist beforehand. Bakir agrees to make an appointment and to allow Imam Abdelrahman to confer with the psychiatrist to appraise him of the situation.

During the consultation, the psychiatrist writes out prescriptions for a selective serotonin reuptake inhibitor and a benzodiazepine. Bakir expresses concern to the psychiatrist that taking this medication may be contrary to his religious belief, which is to rely on God alone. The psychiatrist refers him back to Imam Abdelrahman to address this concern. When Bakir meets with Abdelrahman, the imam reassures Bakir that taking the medicine is okay. After 4 weeks of treatment, Bakir's worries lessen considerably and his panic attacks have stopped.

The above vignette illustrates how religious and mental health professionals can work together to optimise patients' mental healthcare. Such combined care is possible only when each professional appreciates and respects what the other has to offer.

\section{Evidence-based religious/spiritual interventions}

Evidence-based religious/spiritual interventions include (a) secular psychotherapy or pharmacotherapy provided in a way that respects and supports the patient's religious/spiritual beliefs and (b) religiously/spiritually integrated psychotherapy (RSIP) that integrates the patient's beliefs into therapy.

\section{Secular psychotherapy and pharmacotherapy}

Standard evidence-based psychiatric treatments can be provided in a manner that respects and supports the patient's religious/spiritual beliefs (or lack thereof) after conducting a thorough spiritual history. There is little controversy over the provision of holistic care that is consistent with and supportive of patients' religious/spiritual and cultural beliefs. When religious issues come up during treatment, they are valued and treated with respect, knowing that religion is often an important and beneficial resource for patients and their families. 


\section{Religiously/spiritually integrated psychotherapy (RSIP)}

For religious or spiritual patients with emotional problems, religious/spiritual beliefs and practices may be integrated into psychotherapy. RSIP has been shown to be efficacious in the treatment of depression, anxiety, relationship problems and other distressing emotional conditions, and may be more effective than conventional treatments with religious patients (Captari 2018). Examples of such treatments are religious cognitive-behavioural therapy (RCBT) and spiritually integrated cognitive processing therapy (SICPT).

\section{Religious CBT}

RCBT uses an existing evidence-based secular psychotherapy framework (CBT) while integrating the patient's religious beliefs/practices into the therapy, guided by the sacred scriptures or teachings of the patient's religion. Structured RCBT interventions have been developed for patients from Christian, Jewish, Muslim, Hindu and Buddhist faith traditions to treat depression in the setting of chronic medical illness. RCBT has been shown to be as efficacious as conventional CBT (CCBT), and more so than CCBT in highly religious patients (Koenig 2015). The within-group effect size for RCBT is large $(d=$ 3.02 for RCBT v. $d=2.39$ for CCBT) and the between-group comparison slightly favours RCBT $(d=0.12)$, with a significant group $\times$ religiosity interaction (Koenig 2018, p. 270). Manuals and workbooks are available to download free of charge on the Duke University Center for
Spirituality, Theology and Health website (https:// spiritualityandhealth.duke.edu/index.php/religiouscbt-study/therapy-manuals).

\section{Spiritually integrated cognitive processing therapy (SCIPT)}

SICPT was designed for the treatment of 'moral injury' in the setting of post-traumatic stress disorder (PTSD). Preliminary results from a singlegroup experimental study (O'Garo 2020) and an ongoing randomised controlled trial in veterans (Ames 2020) suggest that this approach may also be effective in reducing PTSD symptoms. SICPT utilises a CPT framework (a proven treatment for PTSD) to integrate patients' religious/spiritual resources into the treatment of moral injury. Versions have been developed for Christians, Jews, Muslims, Hindus, Buddhists and those who are more broadly spiritual (Pearce 2018; Koenig 2019, pp. 248-269).

\section{Identifying appropriate patients}

Since the effectiveness of RSIP depends in part on the particular patient, it is necessary to choose wisely when engaging in this form of treatment or referring patients. Patients who are religious and prefer this approach are the best candidates, although there are also other indications (Box 1).

\section{When religion is the problem}

Although many studies indicate that religious/spiritual beliefs and practices can enhance mental health, increase well-being and deepen resilience in the face of trauma or loss, religion does not always

BOX 1 Identifying patients for whom religiously/spiritually integrated psychotherapeutic approaches are indicated

\section{Indicated}

Individuals who request religiously/spiritually integrated psychotherapy (RSIP)

Deeply religious or spiritual individuals, whether RSIP is requested or not

Individuals who report that their religious beliefs have been helpful when coping with stress

Individuals who use religious words and language during interactions with the clinician

Religious individuals from Africa or the Middle East, where religion is part of culture, tradition and lifestyle

Individuals who were previously deeply religious, but something has changed
Individuals with religious or spiritual struggles who are willing to try this approach

Individuals whose emotional problems are relatively mild and intertwined with religious beliefs

Religious individuals facing significant losses or severe situational stressors without significant underlying psychopathology

Not usually indicated

Individuals who prefer standard secular psychotherapy

Individuals who are not religious or spiritual, especially those who have never been

Individuals who had religion forced on them during childhood, with bad experiences
Individuals with a history of significant religious trauma (whether emotional, physical or sexual abuse), unless these issues have been worked through with them during therapy

Individuals with deep underlying psychopathology intertwined with religious beliefs who need psychodynamic therapy first

Psychopathic or highly manipulative individuals forced into therapy by the courts

Individuals who are actively suicidal or homicidal Individuals with active psychotic symptoms Children under 10 years of age (although there may be exceptions here)

Children or adolescents under 18 years of age without parental consent for RSIP

(Based on Koenig 2018, pp. 279-293) 
do so. In some cases, religion may be the problem; in others, religious struggles can cause significant distress or be a manifestation of the illness. The clearest example is the patient with schizophrenia or bipolar disorder who presents with religious delusions or hallucinations, which are symptoms of the underlying disorder and vary depending on religious and cultural context (Koenig 2011). A less obvious example is the use of religion in a neurotic manner, which is often driven by anxious, compulsive or hysterical tendencies. In these cases, religion is used defensively to avoid making changes in attitude and behaviour necessary to improve mental health and relationships with others. Similarly, the rigid, inflexible application of religious teachings (which initially provided comfort and relief) can cause significant interpersonal conflict and mental distress.

Given space limitations, we briefly summarise four cases described in detail elsewhere (Koenig 2018, pp. 297-302), illustrating how patients can use religion neurotically. In the first case, a 68-year-old man with bipolar disorder used religious beliefs to justify a potentially harmful decision to stop his medication, refusing input from others and insisting that he had been miraculously healed of his mental disorder. In the second case, a charismatic, intelligent, handsome 33-year-old individual with a history of emotional abuse and neglect during childhood manipulated his way into a position of power and authority in his religious congregation, demanding the attention and resources of others to fill his neurotic need for control. In the third case, a psychologically and socially insecure 43-year-old divorced woman was convinced to join a religious group that ultimately dominated her life and took over her finances. In the final case, a 61year-old religious individual held rigidly onto religious beliefs that created stress and conflict with family members, illustrating what may happen when an individual chooses a religion different from that of their family of origin. These four cases illustrate patients who manipulate, abuse or misinterpret religion, are abused by religion (or religious leaders), or experience interpersonal conflict and distress when religious change occurs.

\section{Clinical approach}

How, then, might mental health professionals best deal with problematic aspects of religion? We do not recommend that clinicians directly challenge or seek to alter a patient's religious/spiritual beliefs, even when these are causing problems. There are more effective approaches than arguing with patients about their religious beliefs or pointing out how those beliefs are contributing to their psychiatric problems. Such approaches are usually not effective, may alienate the patient, harm the clinician-patient relationship and fail to respect patient autonomy. If religious beliefs are neurotic or pathological, it is usually because of deep unresolved issues that religion is used to defend against. Pathological religious beliefs are often held tightly by these individuals, and no amount of rational persuasion will likely alter them. Efforts to do so may cause the patient to distrust the clinician and lead to non-adherence or dropping out of treatment.

Instead, we recommend that clinicians act 'harmlessly inquisitive' as they seek to learn more about these patients' religious/spiritual beliefs. In a friendly, caring and gentle manner, the clinician can pursue a Socratic line of questioning, asking for details of what the patient believes and occasionally pointing out inconsistencies in their logic and departure from core beliefs taught by their religious tradition. It can be helpful to see the situation in light of the patient as teacher and the clinician as student. This may necessitate learning more about what the patient's religion teaches and may even require involvement of a member of the patient's clergy, as suggested earlier. This gentle approach will help convince the patient that the clinician is on their side, cares about them and simply wishes to better understand their religious/spiritual beliefs, thus not requiring the patient to defend or justify those beliefs. This can help the patient to gradually become aware of contradictions in their logic and eventually become open to suggestions on how to deal with underlying conflicts. The patient must view the clinician as an advocate for them and their sacred beliefs, not as an enemy of their faith, which must be defended at all cost. Working at the religion/psychiatry interface can at times be complex, although there is a large and growing literature on how to proceed (Peteet 1994; Abernethy 1998; Peteet 2018).

\section{Conclusions}

General clinical applications relevant to the treatment of all patients include taking a spiritual history, supporting or encouraging religious practices and communal participation and, perhaps more controversially, occasionally engaging in religious practices with patients. Referral to or cotherapy with clergy may also be considered. Evidence-based religious interventions exist that may be useful with patients who prefer a religious/ spiritual approach. In some cases, religious/spiritual beliefs and practices may be the problem, and these should be dealt with carefully. Given space limitations, we have not discussed the impact of religiosity on abortion, homosexuality or 
MCO answers

$1 \mathrm{~d} \quad 2$ e $\quad 3 c \quad 4 d \quad 5 c$ extremism, topics that deserve discussion in their own right. Knowing how to take a spiritual history, sensitively engage with religious and nonreligious patients and care for patients who are struggling with religious/spiritual beliefs are skills that can and must be learned.

\section{Author contributions}

H.G.K. contributed to the conception and design of this article, drafted and revised the work, providing important intellectual content, and approved the final version of the manuscript. J.R.P. contributed to the conception and design of this article and drafting of the work, providing important intellectual content, and approved the final version of the manuscript. T.J.V. contributed to the conception and design of this article, helped to revise the work, providing important intellectual content, and approved the final version of the manuscript. All three authors are accountable for all aspects of this work in terms of its accuracy and integrity.

\section{References}

Abernethy AD, Lancia JJ (1998) Religion and the psychotherapeutic relationship: transferential and countertransferential dimensions. Journal of Psychotherapy Practice and Research, 7: 281-9.

American Psychiatric Association Committee on Religion and Psychiatry (1990) Guidelines regarding possible conflict between psychiatrists' religious commitments and psychiatric practice. American Journal of Psychiatry, 147: 542.

Ames D, Koenig HG (2020) Randomized Controlled Trial Comparing Conventional Cognitive Processing Therapy (CPT) with SpirituallyIntegrated CPT and Structured Chaplain-Administered Pastoral Care in U.S. Veterans with Moral Injury and PTSD Symptoms (IRB\# PCC 2018050499). VA Greater Los Angeles Healthcare System.

Captari LE, Hook JN, Hoyt W, et al (2018) Integrating clients' religion and spirituality within psychotherapy: a comprehensive meta-analysis. Journal of Clinical Psychology, 74: 1938-51.

Cook CCH (2013a) Recommendations for Psychiatrists on Spirituality and Religion (Position Statement PS03/2013). Royal College of Psychiatrists.

Cook CCH (2013b) Controversies on the place of spirituality and religion in psychiatric practice. In Spirituality, Theology and Mental Health (ed CCH Cook): 1-19. SCM Press.

Crabtree S (2009) Religiosity highest in world's poorest nations. Gallup Poll, 31 August. Gallup (https://news.gallup.com/poll/142727/ReligiosityHighest-World-Poorest-Nations.aspx\#1). Accessed 13 December 2019

Dagi TF (1995) Prayer, piety and professional propriety: limits on religious expression in hospitals. Journal of Clinical Ethics, 6: 274-79.

Franzblau AN, D'Agostino A, Draper E, et al (1975) Psychiatrists Viewpoints on Religion and Their Services to Religious Institutions and the Ministry (Taskforce Report 10). American Psychiatric Association (https://www.psychiatry.org/File\%20Library/Psychiatrists/Directories/ Library-and-Archive/task-force-reports/tfr1975_Religion.pdf).

Koenig HG (2005) Faith and Mental Health: Religious Resources for Healing. Templeton Foundation Press.
Koenig HG (2011) Schizophrenia and other psychotic disorders. In Religious and Spiritual Issues in Psychiatric Diagnosis: A Research Agenda for DSM-V (eds J Peteet, FG Lu, WE Narrow): 31-52. American Psychiatric Publishing.

Koenig HG, King DE, Carson VB (2012) Handbook of Religion and Health (2nd edn). Oxford University Press

Koenig HG (2013) Spirituality in Patient Care (3rd edn). Templeton Foundation Press.

Koenig HG, Pearce MJ, Nelson B, et al (2015) Religious vs. conventional cognitive behavioral therapy for major depression in persons with chronic medical illness: a pilot randomized trial. Journal of Nervous and Mental Disease, 203: 243-51.

Koenig HG (2018) Religion and Mental Health: Research and Clinical Applications. Academic Press

Koenig HG, Ames D, Pearce M (2019) Religion and Recovery from PTSD. Jessica Kingsley Publishers.

Koenig HG, Al-Zaben F, VanderWeele TJ (2020) Religion and psychiatry: recent developments in research. BJPsych Advances, 26: in press.

Larson DB, Thielman SB, Greenwold MA, et al (1993) Religious content in the DSM-III-R glossary of technical terms. American Journal of Psychiatry, 150: $1884-5$.

Mathai J, North A (2003) Spiritual history of parents of children attending a child and adolescent mental health service. Australasian Psychiatry, 11: $172-4$.

Miller L, Bansal R, Wickramaratne P, et al (2014) Neuroanatomical correlates of religiosity and spirituality: a study in adults at high and low familial risk for depression. JAMA Psychiatry, 71: 128-35

Moreira-Almeida A, Sharma A, van Rensburg BJ, et al (2016) WPA position statement on spirituality and religion in psychiatry. World Psychiatry, 15: 87-8.

Neeleman J King MB (1993) Psychiatrists' religious attitudes in relation to their clinical practice: a survey of 231 psychiatrists. Acta Psychiatrica Scandinavia, 88: 420-4.

O'Garo KG, Koenig HG (2020) Pilot trial of spiritually-integrated cognitive processing therapy in Veterans and Active Duty Military (IRB\# Pro00084666). Duke University Center for Spirituality, Theology and Health.

Pearce M, Haynes K, Rivera NR, et al (2018) Spiritually integrated cognitive processing therapy: A new treatment for post-traumatic stress disorder that targets moral injury. Global Advances in Health and Medicine, 7: 1-7.

Peteet JR (1994) Approaching spiritual problems in psychotherapy: a conceptual framework. Journal of Psychotherapy Practice \& Research, 3: $237-45$

Peteet JR, Dell ML, Fung WLA (eds) (2018) Ethical Considerations at the Intersection of Psychiatry and Religion. Oxford University Press.

Peteet JR, Al-Zaben F, Koenig HG (2019) Integrating spirituality into the care of older adults. International Psychogeriatrics, 31: 31-8.

Poole R, Cook CCH (2011) Praying with a patient constitutes a breach of professional boundaries in psychiatric practice. British Journal of Psychiatry, 199: 94-8.

Poole R, Cook CCH, Higgo R (2019) Psychiatrists, spirituality and religion. British Journal of Psychiatry, 214: 181-2.

Sanua VD (1969) Religion, mental health, and personality: a review of empirical studies. American Journal of Psychiatry, 125: 1203-13.

VanderWeele TJ, Li S, Tsai AC, et al (2016) Association between religious service attendance and lower suicide rates among US women. JAMA Psychiatry, 73: 845-51.

VanderWeele TJ (2017) Religious communities and human flourishing. Current Directions in Psychological Science, 26: 476-81. 
MCOs

Select the single best option for each question stem:

1 A spiritual history may be considered with:

a religious patients only

b spiritual patients only

c in-patients only

d all patients

e religious or spiritual patients.

2 Mental health professionals are obligated to:

a pray with patients when asked

b share their personal religious/spiritual beliefs with patients if requested

c prescribe religion to non-religious patients

d challenge patients' religious/spiritual beliefs

e show respect for patients' religious/spiritual beliefs.
3 With patients seeking mental healthcare it is not appropriate to:

a take a spiritual history

b support the patients' own religious beliefs and practices

c convince patients to believe as the mental health professional believes

d encourage socially isolated religious patients to engage in their religious community

e refer religious patients to a pastoral counsellor for co-therapy.

4 Religiously/spirituality integrated psychotherapy may be beneficial for:

a patients who are agnostic or atheist who would benefit from religion

b children under 10 year of age

c religious patients only, specifically Christians

d religious or spiritual patients who prefer this approach

e spiritual patients only.
5 When religious beliefs appear to be the problem, clinicians should first:

a rationally explain to the patient how their beliefs are contributing to their mental health problems

b challenge the patient about the irrational nature and inconsistency of their beliefs

c ask about, listen to and learn more about the patient's beliefs

d recommend that the patient becomes less religious

e tell the patient that their religious beliefs are the cause of their illness. 